\title{
¿CABE APLICAR LA EQUIDAD A LA LEY NATURAL? LA RESPUESTA DE FRANCISCO SUÁREZ*
}

\section{JOAQUín GARCíA-HUIDOBRo**}

RESUMEN: Como consecuencia de su distinción entre cosas justas por naturaleza y cosas que lo son por convención, Aristóteles se ve obligado a desarrollar su doctrina de la equidad, que permite realizar un ajuste entre los enunciados de la norma, necesariamente generales, y la singularidad del caso concreto. Esta enseńanza aristotélica fue recibida por los autores del Siglo de Oro español, que debieron, a su vez, resolver la cuestión de si la equidad se aplica solo a la ley positiva o si también procede en el caso de la ley natural. En este artículo se expone la solución de Francisco Suárez a este problema, quien muestra que la equidad no tiene lugar tratándose de la ley natural y que los ejemplos que señalan los autores que afirman esta posibilidad son más bien casos de interpretación. Termina el artículo tratando algunos problemas que suscita la posición de Suárez en su aplicación a los casos del incesto y la poligamia.

PALABRAS CLAVE: Ley natural - equidad - Francisco Suárez - poligamia - incesto.

\section{IS EQUITY APPLICABLE TO NATURAL JUSTICE? THE ANSWER OF FRANCISCO SUÁREZ}

ABSTRACT: As a consequence of Aristotle's distinction between issues that are fair by nature and those that are not by conventions, he is forced to develop his doctrine of equity that allows an adjustment to the

Este trabajo forma parte de un proyecto más amplio, patrocinado por FONDECYT No 1080214. El autor agradece las observaciones de los profesores J. Cruz, I. Zorroza, L. Corso de Estrada, D. Herrera, A. Miranda y C. Orrego. Una primera versión muy resumida de este trabajo se publicó en: (2009). "Equidad y ley natural", en: Cruz Cruz, J. (ed.): La gravitación moral de la ley según Francisco Suárez, Pamplona: Eunsa, pp. 95-108.

Fecha de recepción: 30 de noviembre de 2010.

Fecha de aceptación: 27 de diciembre de 2010.

** Licenciado en Derecho por la Universidad de Chile y Doctor en Filosofía por la Universidad de Navarra (España). Profesor de Ética y Filosofía Jurídica en la Universidad de los Andes (CHILE). Correo electrónico: jgh@uandes.cl 
statements of the norm, that are necessarily general, and the singularity of the concrete case. This Aristotelian teaching was received by authors belonging to the Spanish Golden Age, that had to solve as well the question about the applicability of equity only to positive law or if it also proceeds in the case of natural law. This article presents the solution by Francisco Suárez to this problem, who shows that equity has no place when dealing with natural law and that the examples the authors point out that state this possibility are rather cases of interpretation. The article concludes dealing with some problems that arouses Suárez's position applied to cases of incest and polygamy.

KEY WORDS: Natural Justice - equity - Francisco Suárez - polygamy incest.

En el capítulo 7 del libro V de la Ética a Nicómaco, Aristóteles formula la célebre distinción entre cosas que son justas por naturaleza y aquellas que lo son por convención ${ }^{1}$. Esta doctrina tiene algunos antecedentes en Platón, particularmente en la distinción que hace Sócrates en el Eutifrón entre cosas que están prohibidas porque son malas y cosas que son malas porque están prohibidas ${ }^{2}$. Estas últimas vienen a corresponder a la justicia convencional aristotélica. Se trata, en efecto, de una distinción importante, que está en la base de la Tradición Central de la ética occidental. Sin embargo, una vez que se acepta esta doctrina se plantea de inmediato el problema de cómo se compaginan ambas formas de justicia. Este problema presenta dos facetas: una, la más conocida, está representada por la posible colisión entre los dictados de la justicia convencional, expresados en las leyes positivas, y las exigencias de la justicia suprapositiva. Este conflicto ya fue descrito por Sófocles en Antígona y recorre toda la historia de la filosofía, por ejemplo, a propósito de la ley injusta. La otra faceta, en cambio, tiene que ver con la forma en la que nosotros debemos concretar las exigencias de la justicia natural. Dicho con otras palabras, por mucho que se admita la existencia de una justicia natural, resulta imprescindible recurrir a ciertas mediaciones para hacerlas efectivas. La vía por la que se produce este proceso de determinación es de ordinario, la ley positiva.

Con todo, nada asegura que este proceso de mediación entre las exigencias de la justicia natural y su concreción legislativa sea siempre eficaz. En efecto, resulta evidente que la inteligencia de quienes intervienen en

Ética a Nicómaco, V, 7 1134b18-1135a5 (se empleará la traducción de E. Sinnot (2007), Buenos Aires: Coligüe.

2 Platón (1997). Eutifrón, Santiago: Universitaria, traducción, análisis y notas: Alfonso Gómez-Lobo. 
esa convención no es capaz de prever todas las situaciones posibles que pueden presentarse. Y, puesto que el legislador dispone para los casos ordinarios, bien puede suceder que la presencia de circunstancias excepcionales lleve a que una ley que es perfectamente razonable en situaciones normales produzca un resultado injusto en una situación de excepción. En estos casos, enseña Aristóteles, hay que resolver el asunto de la manera en que lo habría hecho el legislador y no apegarse en exceso a la letra. Allí tiene lugar la epieikeia ${ }^{3}$. Al apartarse de la letra de la ley, el juez "no elimina aspectos de la justicia, sino que, al contrario, encuentra un derecho mejor" ${ }^{\text {. }}$. Hasta ahí, resumida, la solución de Aristóteles al problema de la tensión entre la generalidad de la ley y la variabilidad de las circunstancias del caso concreto.

El hecho de que algunos autores de inspiración hermenéutica piensen que la equidad no es un recurso extraordinario sino un mecanismo que siempre debe estar presente a la hora de ajustar los criterios de la norma general a las exigencias del caso concreto ${ }^{5}$, no cambia el fondo de la cuestión, que consiste en que la equidad tiene su lugar propio tratándose de los criterios de justicia convencional y apunta a que esta forma de justicia no se aplique de una manera tal que termine por lesionar lo que es justo por naturaleza. Hay que tener en cuenta que para Aristóteles, que no tiene una teoría de la ley natural ${ }^{6}$, la ley es, en principio, la ley positiva, esté o no puesta por escrito ${ }^{7}$. Por tanto, solo respecto de ella procede

3 " $[\mathrm{L}] \mathrm{o}$ equitativo es justo, pero no [lo justo] según la ley, sino una corrección de lo justo legal. La causa es que toda ley es general, y hay cosas de las que no es posible expresarse correctamente en forma general. Entonces, en los casos en que es necesario expresarse en términos generales pero no es posible hacerlo correctamente, la ley considera lo que se da las más de las veces, sin ignorar el error. Y no es [por eso] menos correcta, pues el error no está en la ley ni en el legislador, sino en la naturaleza de la cosa, pues tal es, sencillamente, la materia de las [cuestiones] concernientes a la acción. Por tanto, cada vez que la ley habla en términos generales, pero de hecho se da, en lo que atañe a ella, algo [que está] al margen de lo general, entonces es acertado, allí donde el legislador no atendió a algo y cometió un error por hablar en sentido absoluto, corregir la omisión; eso diría el propio legislador de estar ahí presente; y si hubiese previsto [el caso particular en cuestión], [lo] habría incluido en la ley. Por eso [lo equitativo] es justo, y mejor que cierta forma de lo justo, pero no mejor que lo justo en sentido absoluto, sí [es] mejor que el error causado por [el hecho de expresarse] en sentido absoluto. Y esa es la naturaleza de lo equitativo: ser corrección de la ley en tanto esta incurre en omisiones a causa de su índole general" (EN V 10, 1137b11-27).

4 Gadamer, Hans-Georg (1990). Wahrheit und Methode. Grundzüge einer philosophischen Hermeneutik, 6a edición. Tübingen: J. C. B. Mohr, p. 323 (trad. A. A. Aparicio y R. de Agapito, Salamanca, 2005).

$5 \quad$ Véase, por ejemplo, Ollero, Andrés (1974). "Hermenéutica jurídica y ontología en Tomás de Aquino". Anuario de Estudios Sociales y Jurídicos, III, pp. 289-303 y (1973) "Equidad, derecho, ley". Anales de la Cátedra Francisco Suárez, 13, pp. 163-178.

6 Así, Voegelin, Eric (2006). „Das Rechte von Natur”, en Voegelin, Eric: Anamnesis. Zur Theorie der Geschichte und Politik. Freiburg-München: Alber, pp. 117-133.

7 Dice Aristóteles en la Retórica: "Divido la ley en particular y común: particular, la establecida para cada pueblo respecto de él mismo, y esta es en parte no escrita y en parte escrita. Común es la ley conforme a la naturaleza. Pues de acuerdo con esta existe algo comúnmente 
la equidad, que permite superar las limitaciones derivadas tanto de nuestro lenguaje como de la necesaria generalidad que debe revestir la ley. La equidad, por tanto, no se da respecto de lo justo natural porque, para decirlo en palabras de Aristóteles, lo equitativo no es mejor que "lo justo en sentido absoluto" ${ }^{8}$, sino que constituye tan solo una corrección de la justicia que se expresa en normas positivas.

Tenemos, entonces, que en la filosofía práctica de Aristóteles la ley es la ley positiva, sin perjuicio de que admita la existencia de cosas que son justas por naturaleza, si bien ellas no se expresan en términos normativos. Sin embargo, por influencia del estoicismo y, más específicamente, de Cicerón, la tradición medieval aludió a otro tipo de ley, situada más allá de la positiva, a la que asignó una importancia decisiva, a saber, la ley natural $^{9}$. Surge así la distinción estoica y medieval entre ley natural y ley positiva, que corre paralela a la diferencia aristotélica entre cosas justas por naturaleza y cosas justas por convención. Con todo, ambas distinciones no se confunden, entre otras razones, porque la ética de Aristóteles no tiene un carácter normativista, cosa que sí comienza a suceder en el mundo medieval, cuando la reflexión moral es enriquecida por la incorporación de la noción de ley natural.

En todo caso, a partir del siglo XIII, la noción estoica y cristiana de ley natural comienza a ser entendida por varios autores medievales de una forma fuertemente aristotélica. En efecto, si bien son muchos los textos de esa época donde se concibe la ley natural como una participación de la ley eterna en la criatura racional ${ }^{10}$-que es, por decirlo así, el modo no aristotélico de plantear la cuestión-, desde Guillermo de Auxerre se abre paso otro modo de argumentar, basado en el pensamiento del Estagirita ${ }^{11}$. En efecto, si en la Metafísica se dice que la razón especulativa funciona presuponiendo siempre ciertos principios que tienen el carácter de primeros y que, por tanto, son inderivados e indemostrables ${ }^{12}$, ¿̇no sucederá lo

justo e injusto, lo cual todos adivinan, aunque no exista ningún acuerdo común entre unos y otros pueblos, ni pacto alguno; así como se nos presenta Antígona en Sófocles cuando dice que es justo sepultar a Polinices, cuya inhumación estaba prohibida, como quiera que esto es justo por naturaleza, 'porque esto no es de ahora, ni de ayer, sino que existió siempre, y nadie sabe de dónde procede"” (I 13 1373b4-12, la cita de Antígona procede de los vv. 4567). Se emplea: Aristóteles (2007). Retórica, introducción, traducción y notas de Quintín Racionero, Madrid: Gredos.

$8 \quad E N \mathrm{~V} 10,1137 \mathrm{~b} 24$.

9 Corso de Estrada, Laura (2008). Naturaleza y vida moral. Un estudio sobre el influjo filosófico de Marco Tulio Cicerón en Tomás de Aquino. Pamplona: Eunsa. Un intento reciente de disminuir la influencia estoica en el Aquinate: Scherz, Luis T. (2006). Das Naturgesetz bei Thomas von Aquin und die Tentatio Stoicorum, heutige Auffassungen eines umstrittenen Begriffs, Tübingen: Francke Verlag.

10 Tomás de Aquino, Suma Teológica, I-II, 90, 2.

11 Así, por ejemplo, Summa aurea, II, tr. 10, cap. 6, q. 1, 122-125 (C. N. R. S., Paris, 1980, cura et studio de Jean Ribaillier).

12 Met. IV 4, 1006a6-12. 
mismo en el campo práctico? Guillermo y, posteriormente, santo Tomás piensan que sí e identifican el orden de los preceptos de la ley natural con el de los principios de la razón práctica:

"Hay que reconocer en la razón práctica algo que sea respecto de las operaciones lo que la proposición en la razón es respecto de las conclusiones. Y estas proposiciones universales de la razón práctica ordenadas a los actos tienen carácter de ley"13.

Este modo de presentar la teoría de la ley natural ha tenido especial fortuna en las últimas décadas, particularmente entre aquellos autores que están interesados en mostrar que la ética presenta una cierta autonomía respecto de la metafísica ${ }^{14}$. Estos autores se muestran reticentes frente a la utilización, en contextos prácticos, de la idea de participación a partir de la ley eterna. En todo caso, no aceptan que esa sea la característica definitoria de la ley natural. Les parece que esos modos argumentar, aunque tradicionales, resultan muy vulnerables a la crítica que, al menos desde Hume, se hace al intento de extraer principios morales a partir de ciertos estados de $\operatorname{cosas}^{15}$. De ahí, entonces, la importancia que le atribuyen a la comprensión de la ley natural mediante la categoría intelectual de los principios de la razón práctica, en vez de la categoría metafísica de participación.

La identificación de la ley natural con los principios de la razón práctica está presente no solo en santo Tomás sino también, con diversos matices, en sus discípulos espańoles del Siglo de Oro ${ }^{16}$. A ellos, sin embargo, se les plantea un problema, que no tenía Aristóteles y que santo Tomás no trata directamente, a saber, si la equidad (llamada por ellos epikeia o epiikeia) se aplica solo a la ley positiva o si también vale tratándose de la ley natural. De ese problema se ocupa Francisco Suárez en el capítulo

13 S. Th. I-II, 90, 1, ad 2; también: I-II, 94, 2c, etc. La cita de santo Tomás recogida más arriba se aplica a todo tipo de leyes pero de modo principal a la ley natural.

14 Un panorama de estas posturas en Massini, Carlos I. (1997). "La nueva escuela anglosajona de Derecho Natural", en Revista de Ciencias Sociales, No 41, pp. 371-392. El empeño por separar la ética de la metafísica se debe, en buena medida, a la crítica de Hume a la pretensión de derivar principios morales a partir de observaciones sobre la naturaleza: Hume, David (1977). Tratado de la naturaleza humana, vol. II, Madrid: Editora Nacional, pp. 689-690.

15 Un panorama de este tipo de problemas en Massini, Carlos I. (1995). La falacia de la falacia naturalista, Mendoza: Edium, pp. 17-79 y Höffe, Ottfried (1988). "Derecho natural sin falacia naturalista: un programa jusfilosófico". En él mismo: Estudios sobre teoría del derecho y la justicia. Barcelona: Editorial Alfa, pp. 105-132.

16 Véase: De Legibus II, V, 10 [118a], II, V, 12 [119a], etc.; De Soto, Domingo (1922). Tratado de la Justicia y del Derecho, I, 4, 1, Madrid: Reus; Herrera, Hugo (2000). Verdad y práctica. Cinco ensayos sobre la fundamentación de la praxis. Valparaíso: Edeval, pp. 39-68. 
XVI del libro II del De Legibus ${ }^{17}$. Para resolver este problema se mostrará la diferencia que hace Suárez entre equidad e interpretación (1), las razones que lo llevan a pensar que no procede la equidad en el caso de la ley natural (2) y, finalmente, se harán algunas aplicaciones de este problema al caso del matrimonio (3 y 4 ).

\section{1) LA DIFERENCIA ENTRE EQUIDAD E INTERPRETACIÓN}

La pregunta de si cabe aplicar la equidad en el caso de la ley natural supone hacer una clarificación, pues Suárez enseńa que la ley natural puede considerarse tanto en sí misma como en cuanto sus preceptos están recogidos en las leyes positivas: "La ley natural puede considerarse o en sí misma, tal como la recta razón la concibe o dicta, o tal como otras leyes escritas la expresan con determinadas fórmulas" ${ }^{18}$. En efecto, son numerosas las normas positivas que determinan o especifican los principios naturales. En este caso de las leyes positivas, es claro que procede recurrir a la equidad, ya que se trata de un mecanismo corrector de la necesaria generalidad de esas normas. El problema, en cambio, se presenta cuando atendemos a la ley natural considerada en sí misma. Aquí, la idea central de Suárez es que no procede la epiqueya en el caso de la ley natural, sino solo la interpretación. Piensa, en efecto, que este es un concepto más amplio que el de equidad, aunque en cierto sentido lo incluye, pues "toda epiqueya es interpretación de la ley, pero no toda interpretación de la ley es epiqueya" ${ }^{19}$. Siguiendo a Cayetano, estima nuestro autor que

"muchas veces, o más bien siempre, las leyes necesitan de interpretación por la oscuridad o ambigüedad de sus fórmulas o por alguna otra razón semejante, pero [...] no todas estas interpretaciones

17 Ya antes, dentro del mismo libro, se había ocupado de este tema, cuando distinguía entre la equidad entendida como "lo equitativo en cuanto sinónimo de lo justo natural" (De Legibus I, II, 9 [13a]) y la equidad en sentido estricto, que es el de una "prudente suavización de la ley escrita, al margen del rigor de sus palabras" (De Legibus I, II, 10 [13b]) para evitar que, en casos especiales, su aplicación resulte "contraria a la equidad natural" (De Legibus I, II, 10 [13a]), es decir, a la equidad tomada en el primer sentido. En términos generales, reserva la palabra aequitas para el primer uso y epiikia para el segundo. Se cita según la edición bilingüe que reproduce la edición príncipe de Coimbra (1612), indicando entre corchetes la página y columna de la misma: Suárez, Francisco (1967). Tratado de las leyes y de Dios Legislador en diez libros (traducción de J. R. Muniozguren). Madrid: Instituto de Estudios Políticos. En todo caso, ya al comienzo de su carrera Suárez se había ocupado del tema de la equidad, en sus Quaestiones de Iustitia et Iure, Disputatio quarta, q. 5, en Giers, Joachim (1958). Die Gerechtigkeitslehre des jungen Suárez. Edition und Untersuchung seiner römischen Vorlesungen De Iustitua et Iure. Freiburg: Herder.

18 De Legibus II, XI, 5 [174b].

19 De Legibus II, XVI, 4 [174a]. 
son epiqueyas, sino solamente aquellas por las cuales interpretamos que una ley falla en un caso particular por razón de su universalidad, es decir, porque la ley se dio en términos generales y en algún caso particular falla de tal manera que en él no puede observarse justamente" 20 .

Suárez mantiene, como se ve, una concepción de la equidad muy semejante a la de Aristóteles, pero, a diferencia de él, se detiene con cierto detalle en el problema de la interpretación de la ley. Si, como dirá a continuación, lo propio de la epiqueya es el que constituye "una enmienda de la ley", debe tenerse en cuenta que

"puede haber otras interpretaciones que no son enmienda de las leyes sino únicamente explicaciones de su sentido en puntos algo ambiguos; así, por ejemplo, cuando interpretamos si una ley prohíbe el contrato o lo invalida, no hacemos ninguna enmienda de la ley sino que investigamos su verdadero sentido. En esto se diferencia la interpretación en general y la que se hace por medio de la epiqueya" 21 .

En la concepción de Suárez la interpretación es una actividad que se realiza con gran amplitud. Respecto de las leyes positivas ella se realiza "muchas veces, o más bien siempre" 22 . Pero no se queda allí, ya que además entrega diversos argumentos para mostrar que la necesidad de interpretar se aplica no solo a la ley positiva, sino también a la de carácter natural. En efecto, resulta necesario entender el sentido y alcance de las palabras que la expresan, ya que "no todos los preceptos naturales son igualmente conocidos ni igualmente fáciles de entender, y necesitan interpretación para entender su verdadero sentido sin quitar ni añadir nada" 23 . Un caso típico es, para nuestro autor, el del homicidio:

"en el precepto de evitar el homicidio la interpretación es muy necesaria para comprender qué se entiende en él por la palabra homicidio, porque no cualquier muerte de hombre es el homicidio que prohíbe la ley natural, sino la que se perpetra por autoridad particular y directamente, o sea, de intento o en forma de agresión, pero

\footnotetext{
20 De Legibus II, XVI, 4 [174a]. Se ha mantenido la expresión “epiqueya” empleada en la traducción castellana pues, aunque desde el punto de vista lingüístico no es la más adecuada, es la versión aceptada por la Real Academia, cuyo diccionario no contempla la voz "epieikeia".

De Legibus II, XVI, 4 [174a].

De Legibus II, XVI, 4 [174a].

De Legibus II, XVI, 6 [174b].
} 
no la que se ejecuta por legítima autoridad o en forma de prudente defensa" 24 .

Como se ve, en realidad lo que requiere interpretación, más que la ley natural, es nuestra formulación de la misma, las palabras que se emplean para recogerla. No contento con la expansión de la tarea interpretativa al campo de la ley natural, Suárez da un paso más, ya que hace ver que no solo es necesario interpretar por las dificultades que trae consigo el uso del lenguaje. En efecto, sucede que, como las circunstancias influyen en la calificación moral de los actos humanos,

"para entender el verdadero sentido de un precepto natural, es preciso investigar las condiciones y circunstancias en que la acción es mala o buena en sí misma, y esto es lo que se llama interpretación de un precepto natural en su verdadero sentido" 25 .

En suma, la interpretación se refiere ahora a cierto estado de cosas, no solo a normas o palabras y esta nueva forma de interpretación pasa a ser entendida como el caso más propio de interpretación de un precepto natural. Ahora bien, tratándose de intelectos infinitamente superiores al nuestro, como es el caso del divino o el angélico, esta labor interpretativa es ociosa, ya que ellos "ven directamente cómo es cada precepto y la manera y condiciones como se refieren a su materia" 26 . Pero en el caso de los hombres la interpretación del precepto y de los hechos resulta indispensable. En efecto, no siempre sabemos cómo son las cosas, particularmente en el campo práctico, caracterizado por la contingencia, ni cuáles son los criterios más adecuados para conducir nuestras acciones de modo conforme a la razón.

Tenemos entonces que la interpretación no solo se refiere a las palabras que expresan una norma, sino que también tiene lugar en el momento de describir y clarificar el acto y sus circunstancias. En efecto, constantemente nos vemos enfrentados a la necesidad tanto de describir un acto propio o ajeno como de clarificar los contextos en que se da. Muchos siglos después de Suárez, Gadamer dirá que

"la interpretación no se limita a los textos y a la comprensión histórica que se trata de alcanzar en ellos. Todas las estructuras de sentido concebidas como textos, desde la naturaleza (interpretatio naturae, Bacon), pasando por el arte [...], hasta las motivaciones

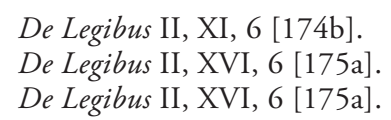


conscientes o inconscientes de la acción humana son susceptibles de interpretación" 27.

De más está advertir que Suárez no diría las cosas de este modo. Ni siquiera resulta claro que piense que toda ley necesita ser interpretada, ya que, aunque admite esta posibilidad, los ejemplos que pone se refieren a leyes que padecen cierta oscuridad. Pero nos parece que la afirmación gadameriana no solo es compatible con lo que Suárez viene diciendo, sino que lo perfecciona. Así, tanto en situaciones diarias del individuo que vive en sociedad como en las relaciones entre los pueblos es necesario saber qué es lo que se tiene enfrente: ¿es una ofensa o solo una distracción la del colega que no nos saluda?; ese determinado país, ¿está procesando uranio para conseguir una energía mejor o es una actividad que se enmarca en el propósito de construir una bomba atómica para iniciar una guerra de agresión? Los actos no son unívocos y la vida humana está necesitada constantemente de un talento interpretativo, que permita poner cada cosa en su sitio y darle la dimensión que realmente tiene. La aptitud para comprender la situación que se tiene delante es decisiva en la vida política y jurídica, tanto para los casos ordinarios como para los extraordinarios. De ahí que ya Aristóteles haya señalado a la synesis y la gnome como capacidades fundamentales para la excelencia moral ${ }^{28}$.

\section{2) LA EQUIDAD NO PROCEDE EN LA APLICACIÓN DE LA LEY NATURAL}

Una vez hechas las necesarias distinciones entre equidad e interpretación Suárez pasa a ocuparse de la postura de aquellos autores que admiten la epiqueya a propósito de la ley natural. Lo hacen apoyados en diversos ejemplos; veamos los dos más importantes, recogidos por Suárez:

"Uno es el de la ley de devolver el depósito. Este ejemplo lo emplea Tomás de Vio, y la interpretación que se da es que no obliga en el caso de que el devolverlo sería contrario a la justicia o a la caridad. Pero esta interpretación no es una epiqueya del mismo precepto natural considerado en sí mismo, porque ese precepto como tal se encuentra en la recta razón, y la recta razón no dicta que se debe devolver el depósito absolutamente sino sobreentendiendo las condiciones que exigen la justicia y la caridad, y así la interpretación que

\footnotetext{
27 Gadamer, Hans-Georg (1993). „Hermeneutik”. En él mismo: Gesammelte Werke 2. Hermeneutik II, Tübingen: J. C. B. Mohr (Paul Siebeck), pp. 434-435. La traducción se toma de Gadamer, Hans-Georg (2002). Verdad y Método II. $5^{\text {a }}$ edición, trad. de M. Olasagasti, Salamanca: Sígueme, p. 372.

28 Véase EN VI 10, 1142b34- VI 11, 1143 b14.
} 
entonces se hace de la ley no es por razón de lo universal -según la expresión de Tomás de Vio- sino que es una explicación de la verdadera universalidad de la misma ley tal como está dada en sí misma, es decir, tal como se contiene en la recta razón. Luego no es una epiqueya" 29 .

Nuevamente nos encontramos con una dificultad que deriva de nuestra formulación lingüística de la exigencia moral natural; decimos: "hay que devolver el depósito", pero en realidad esa formulación incluye una serie de supuestos, como que la devolución se realice de manera racional, que se haga al legítimo dueño, en el momento adecuado, etc. Pensemos un momento en este último caso: ¿qué debe entenderse por "legítimo dueño"? Este no es solo quien posea el título respectivo, sino que, además, debe estar actuando como tal. Cuando una persona reclama las armas para realizar algo injusto o en un momento en que ha perdido el uso de razón, no se está presentando como legítimo dueńo, su dominio no apunta al fin que se supone debe tener el mismo, en suma, ha cambiado su posición dentro del derecho y no puede reclamar lo que se le debía en la medida en que estuviera en la posición anterior. Dicho con otras palabras, en este caso el problema que tenemos delante no es el de devolver un depósito sino el que no resulta lícito colaborar directamente en el mal ajeno (por ejemplo en el homicidio). Por tanto, la norma que se aplica es otra, ya que se trata de un caso de otro tipo.

Lo mismo sucede con algunos ejemplos puestos por Martín de Azpilcueta, como el del precepto "no matarás", que no alcanza a la muerte de un hombre en defensa propia. A la luz de lo visto se advertirá que esta exclusión no sucede por epiqueya, sino por "una sencilla interpretación del verdadero sentido de ese precepto" ${ }^{30}$, como se vio más arriba. Otro tanto ocurre con el juramento, que no incluye el cumplimiento de una promesa ilícita. Piensa Suárez que este tampoco constituye un caso de epiqueya, sino solo "una explicación de la naturaleza del juramento, que consiste en no obligar a nada ilícito" 31 . De hecho, el propio Doctor Navarro reconoce que los anteriores solo aparentemente son casos de epiqueya, pero que en realidad constituyen ejercicios de interpretación.

Hay un tercer caso, que no tendría gran importancia si no fuera porque Martín de Azpilcueta cree que es un genuino ejemplo de epiqueya, a saber, el que a veces se exime al subordinado de la obligación de ley natural de obedecer al superior. Suárez explica que no es así, sino que en realidad no es más que un privilegio, institución de otra naturaleza. Por

De Legibus II, XVI, 7 [175a-b].

De Legibus II, XVI, 7 [175b].

De Legibus II, XVI, 7 [175b]. 
otra parte, en ese caso estamos en presencia de de un cambio de materia, pues allí el subordinado, en lo que al privilegio se refiere, deja de ser tal. Los cambios de materia no constituyen enmienda de la ley y, por tanto, no son ejemplos de epiqueya (y ni siquiera constituyen un caso de interpretación en sentido estricto) ${ }^{32}$.

Después de mostrar que estos y otros ejemplos recogidos por los autores no son casos de equidad, pasa Suárez a dar diversos argumentos para afirmar la exclusión de la epiqueya en la ley natural. En primer lugar, dice, "la epiqueya es una enmienda de la ley o de lo justo legal. Ahora bien, la ley natural no es susceptible de enmienda, ya que consiste en la razón recta, la cual no puede desviarse de la verdad, pues si se desvía ya no es recta" 33 . Es interesante notar que, en el caso de la ley positiva, había que ajustar las palabras de la ley a las exigencias de la recta razón, pero aquí la ley natural consiste precisamente en lo que dicta la recta razón, de modo que no puede tener lugar esa corrección. Lo que sigue supone una distinción importante, a saber, la que se da entre la ley natural y lo justo natural, tema muy importante, que lamentablemente no desarrolla:

"Luego por esa misma razón tampoco puede desviarse lo justo que corresponde a esa ley [natural], pues de tal manera es legal que es también natural. Ahora bien, lo justo natural, procediendo como procede de la conformidad y consonancia -llamémosla así- intrínseca de los extremos, no puede fallar si no cambia alguno de los extremos, y entonces ya cambia la materia de la ley y ya no es el mismo el punto medio de la virtud y -en consecuencia- tampoco es el mismo el justo natural, y así, aunque cambie la obligación de la ley, no es por epiqueya sino por cambio de la materia" 34 .

Mientras en el caso de la ley natural no procede una desviación de la verdad, por la razón ya vista, en el caso de lo justo natural las eventuales mutaciones que se produzcan se explican por un cambio de materia. Tal sería el caso, podríamos decir, de la no devolución del depósito a quien lo reclama de una manera o con una finalidad ilegítima.

En segundo lugar, agrega Suárez, "el dictamen de la recta razón, considerado en sí mismo y como prácticamente verdadero, no se refiere a lo universal en cuanto que puede fallar sino en cuanto rodeado de las circunstancias con las que nunca falla" 35 , de modo que no se presenta el problema de las circunstancias imprevistas, que hacía que en los casos de equidad hubiera que buscar una solución distinta de la expresada por

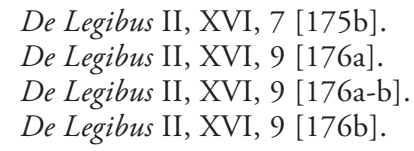


la letra de la ley. "De no ser asî", agrega, "no sería un dictamen verdadero y, en consecuencia, tampoco sería un dictamen necesario ni recto, ni contendría un precepto natural" 36 . En esta afirmación Suárez parece alejarse significativamente de Aristóteles. Pensar que un dictamen deje de ser verdadero porque falle en algún caso no corresponde al carácter de la filosofía práctica, tal como se expresa al comienzo mismo de la Ética a Nicómaco ni a la mutabilidad que en capítulo 7 del libro $\mathrm{V}$ de esa obra se reconoce a las cosas que son justas por naturaleza. Con todo, quizá lo que esté haciendo Suárez, más allá de las palabras que emplee, sea simplemente apuntar al hecho de que en este caso carece de sentido hablar de equidad, pues, en el fondo, no hay una norma general, a la que se escape un caso por su singularidad, ya que el juicio de la razón de que se trata tiene ya un carácter singular. Por eso dice Suárez que el precepto ya se halla "rodeado de las circunstancias en las que nunca falla". ¿Significa esto que dicho precepto ya no es propiamente universal? Tal sería la situación si Suárez hiciera idéntica al juicio de conciencia la ley natural así entendida, pero no es el caso. Nuestro autor piensa que es posible reconocer normas que, sin dejar de ser universales recojan las diversas circunstancia de una manera tal que no admitan falla.

Lamentablemente no desarrolla esta idea, que plantea no pocas dificultades. Una solución sería considerar que Suárez se está refiriendo a los preceptos negativos de la ley natural, los que hoy se llaman absolutos morales, que efectivamente no conocen excepciones ${ }^{37}$, como el mismo Suárez afirma un poco más adelante. Así, un poco más adelante, al hablar de los preceptos naturales que son recogidos en leyes positivas, dice que

"esto [el recurso a la equidad] no tiene lugar en estos preceptos en cuanto naturales, porque como tales no se dan con ninguna palabra general, a no ser que esa palabra incluya todos los elementos necesarios para la malicia intrínseca y de esta forma no pueda admitir excepción, como decíamos acerca del hurto en cuanto hurto o del homicidio en cuanto que es de suyo malo" 38 .

Este pasaje parece avalar la idea de que cuando alude a las circunstancias en que el precepto nunca falla Suárez está pensando en los actos intrínsecamente malos, con lo que nuevamente se acercaría a Aristóteles.

Hay, con todo, otra posibilidad de leer este texto donde se habla de que el precepto está rodeado de las circunstancias en las que nunca falla y

De Legibus II, XVI, 9 [176b].

Aristóteles, Ética a Nicómaco II 6, 1107a9-17.

De Legibus II, XVI, 15 [179b]. 
es a la luz del ejemplo que pone el propio Suárez y que a primera vista no parecería guardar congruencia con lo que viene diciendo:

"de la misma manera que la ciencia filosófica no juzga que todo hombre tiene únicamente cinco dedos de una manera absoluta sino condicional, a saber, si las causas naturales están a punto y no se las impide, y así nunca falla; de otra forma no sería esa una conclusión científica" 39 .

En este sentido, cuando Suárez habla de las circunstancias en las que nunca falla habría que entender que se está refiriendo simplemente a las condiciones normales, del mismo modo en que, en esas condiciones, los hombres tienen cinco dedos en cada mano. En este caso, lo dicho por Suárez sería plenamente aristotélico.

Lo dicho nos lleva a la tercera razón, que es la más interesante desde el punto de vista filosófico, porque en ella distingue Suárez entre preceptos afirmativos y negativos de ley natural. Ellos se distinguen en que los primeros, aunque obligan de modo permanente (semper), no lo hacen en cada momento (pro semper), mientras que los negativos obligan siempre y en cada momento (semper et pro semper) ${ }^{40}$. En este caso, su "naturaleza es obligar siempre y en cada momento evitando lo malo porque es malo" 41 . Esto es esencial a todo precepto negativo natural. Ahora bien, en uno y otro caso la equidad es improcedente. En efecto, en el caso de los preceptos afirmativos,

"no hay excepción de la ley ni enmienda del precepto sino una sencilla mejor comprensión de él [...]. En efecto, si la razón determina que el precepto no obliga en un determinado momento, con eso mismo se entiende que tal precepto, por su misma naturaleza, no se dio para la ocasión y circunstancia que ocurren en aquel tiempo" ${ }^{2}$.

Así, todos estaríamos de acuerdo en decir que uno de los deberes del profesor es estudiar, pero no haría bien quien dejara de dormir o de comer lo necesario con el pretexto de cumplir con la obligación moral de buscar la verdad a través del estudio y la investigación. El precepto de buscar la verdad es muy importante, pero no se ha dado para el momento del sueńo. Lo dicho vale también para resolver uno de los casos mencionados con anterioridad:

De Legibus II, XVI, 9 [176b].

De Legibus II, VIII, 9 [135a].

De Legibus II, XVI, 11 [177a].

De Legibus II, XVI, 10 [177a]. 
"De esta misma manera entiendo el precepto de la devolución del depósito si se lo concibe a manera de precepto afirmativo, pues no obliga en cada momento sino en los tiempos en que pueda cumplirse convenientemente, es decir, devolverse sin perjuicio ni ofensa de otro" 43 .

Como puede verse, Suárez es consciente de que a veces es difícil establecer si un precepto es afirmativo o positivo, pues cabe expresar una misma exigencia moral de una u otra manera (por ejemplo, "hay que devolver el depósito" y "no se debe retener lo dado en depósito"). Eso lleva a que la forma de resolver las aparentes excepciones sea diferente en uno y otro caso, pero lo relevante aquí es que no estamos en presencia de casos de equidad.

Tampoco es posible valerse de la equidad en el caso de los preceptos negativos, que prohíben lo malo porque es malo, ya que "es imposible que lo que es malo de suyo e intrínsecamente se convierta en bueno o en no malo conservándose el mismo objeto y las mismas circunstancias" ${ }^{44}$. Como lo malo nunca deja de serlo, siempre estará prohibido ${ }^{45}$.

"Y si el cambio tiene lugar en el objeto o en sus circunstancias intrínsecas, y por razón de ese cambio el acto deja de ser malo, eso ya no es epiqueya, porque no se refiere a la materia que cae bajo tal ley natural sino que es un conocimiento o interpretación de la materia de la ley y de sus límites" 46 .

Si bien en principio las circunstancias, atendiendo a su etimología, son externas al acto, bien puede hablarse de "circunstancias intrínsecas" para referirse a aquellas que cambian la especie moral. Así, por ejemplo, el que una cosa sea propia o ajena es una circunstancia que nos permite saber si estamos en presencia de un hurto ${ }^{47}$.

De Legibus II, XVI, 10 [177a].

De Legibus II, XVI, 11 [177a].

"Lo que no puede dejar de ser malo, nunca deja de ser malo; luego nunca deja de estar prohibido; luego no puede con verdad declararse que no esté prohibido por la ley natural para algún tiempo u ocasión, que es lo propio de la epiqueya. Y si el cambio tiene lugar en el objeto o en sus circunstancias intrínsecas, y por razón de ese cambio el acto deja de ser malo, eso ya no es epiqueya, porque no se refiere a la materia que cae bajo tal ley natural sino que es un conocimiento o interpretación de la materia de la ley y de sus límites" (De Legibus II, XVI, $11[177 \mathrm{a}])$.

46 De Legibus II, XVI, 11 [177a].

47 "Así, por ejemplo, cuando se interpreta que la ley de no robar no prohíbe cogerle a otro lo necesario para la vida en caso de extrema necesidad, eso no es epiqueya sino una explicación exacta de esa ley, la cual lo único que prohíbe es el hurto, es decir, el coger lo ajeno contra la voluntad razonable de su dueńo, o sea, tomar lo ajeno en cuanto a la propiedad y al uso; ahora bien, el tomar lo ajeno en caso de extrema necesidad, ni es tomar una cosa completa- 
Por si lo anterior no fuera suficiente, Suárez agrega otra explicación, que, en parte, apunta a materias de gran actualidad en el debate ético contemporáneo. Así, cuando se compara la ley positiva con la natural se constata que en la primera es posible que una circunstancia extrínseca haga cesar una obligación, aunque se mantenga la materia y circunstancias intrínsecas del acto. El ejemplo que entrega nuestro autor, recogido de santo Tomás, es la prohibición de llevar armas de noche, que puede darse en un lugar determinado, y que cesa en caso de necesidad urgente, cuando no sea posible solicitar el correspondiente permiso de la autoridad. En este caso, podemos separar el acto de su malicia, en la medida en que desaparezca la prohibición: y cabe pensar que esta es la voluntad razonable del legislador, dadas las nuevas circunstancias. En otros casos, sin embargo, no es posible separar el acto de su malicia:

"En cambio, tratándose de la ley natural, no es admisible que -perseverando entera la materia con las mismas circunstancias intrínsecaspor solas las variantes extrínsecas se interprete que una ley prohibitiva no obligue, porque es imposible que de tal materia rodeada de sus condiciones intrínsecas se separe la malicia y -en consecuencia- la prohibición natural, por más que extrínsecamente varíen el fin o las circunstancias" ${ }^{48}$.

Estas palabras sitúan a Suárez de lleno en aquella tradición que seńala que hay actos que son malos por su objeto, independientemente de la finalidad que se quiera alcanzar con ellos o de las circunstancias que los rodeen $^{49}$. Si en algún caso parece que un precepto natural no obliga, se debe simplemente a que ha cambiado la materia del acto. Suárez lo ejemplifica con la mentira, "la cual doy por supuesto que es tan intrínsecamente mala que por ninguna circunstancia ni necesidad extrínseca puede ser lícita mientras sea mentira" ${ }^{50}$. Porque

"ni el fin extrínseco ni la necesidad extrínseca mudan el objeto ni las condiciones intrínsecas que se requieren para la mentira: este objeto es el único de quien recibe la mentira su fealdad intrínseca, y por eso

mente ajena -porque en un trance así todas las cosas son comunes- ni es contra la voluntad razonable de su dueño. Lo mismo en el caso del depósito: si el precepto se entiende como negativo en el sentido de precepto de restituir, es decir, de no retener el depósito ajeno, no es un precepto tan indeterminado, sino de no retener irrazonablemente, o sea, sin una. causa apremiante. Por consiguiente en los preceptos naturales negativos es inconcebible la verdadera epiqueya" (De Legibus II, XVI, 11 [177a-b]).

48 De Legibus II, XVI, 12 [177b].

49 EN II, 6, 1107 a 9-17; un panorama de esta doctrina en FinNis, John (1992). Absolutos morales, Barcelona: Ediciones Internacionales Universitarias.

50 De Legibus II, XVI, 12 [178a]. 
ni la dispensa ni la epiqueya caben en ella de forma que pueda resultar lícita por ninguna ocasión, necesidad o fin extrínsecos" 51 .

La comparación entre la ley positiva y la natural sirve de base para otro argumento de nuestro autor. En efecto, en el caso de la ley positiva, la equidad no supone que las palabras sean oscuras ni envuelve dudas acerca de que el acto esté prohibido por la norma, tomando las palabras en sentido literal; simplemente hay dudas acerca de la intención del legislador. Sin embargo, en el caso de la ley natural, la razón de las prohibiciones no está en la voluntad legislativa, sino "en la naturaleza misma del acto sustancialmente malo" 52 . No hay, por tanto, que investigar la voluntad de un legislador o de la ley, sino más bien desentrañar la naturaleza del caso que se trata de resolver ${ }^{53}$ :

"Esto [buscar la intención legislativa] no cabe hacerla en la ley natural, porque esta no se funda ante todo en la voluntad que da la prohibición sino en la naturaleza del mismo acto sustancialmente malo, y por eso en ella la interpretación solo cabe acerca de la materia cuando el acto -tomado en abstracto- no tiene malicia intrínsecamente sino únicamente en cuanto que versa acerca de tal materia o tal modo de realizar la acción, según lo hemos explicado en los casos del homicidio, del hurto, de la retención del depósito y otros semejantes.

"Por eso en esta ley no cabe la interpretación en forma de enmienda de la ley -pues esta siempre se ajusta a la materia- sino únicamente en forma de explicación de la cosa y de la malicia que en sí misma tiene, pues únicamente atendiendo a esta se hace la prohibición y se da la ley, sea como manifestación de esa malicia, sea como prohibición de ella" 54 .

De ahí que Suárez afirme que no cabe considerar lícito un acto que es malo por su materia acudiendo a "la intención del legislador con motivo de cualquier circunstancia, necesidad o fin extrínsecos" 55 .

En todas estas argumentaciones, Suárez atiende a la distinción ya aludida entre circunstancias y fines intrínsecos y extrínsecos del acto, que no necesita aclarar porque resultaba conocida a sus lectores. Esta distinción juega un papel fundamental, como se verá a continuación (cf. III).

De Legibus II, XVI, 12 [178a].

De Legibus II, XVI, 13 [178b].

Véase Kaufmann, Arthur (1976). Analogía y naturaleza de la cosa. Hacia una teoría de la comprensión jurídica. Santiago: Editorial Jurídica de Chile.

De Legibus II, XVI, 13 [178b].

De Legibus II, XVI, 13 [178b]. 
En resumen, como señala Suárez, los supuestos casos de equidad en la ley natural no son tales, sino casos en los que ha variado la interpretación, fruto de un cambio en la materia del acto:

"Así pues, siempre que un precepto natural parece no obligar en alguna circunstancia, es preciso que haya cambiado la materia de tal acto, que es lo que le comunicaba la malicia por la cual lo prohíbe la ley natural. Entendidas las cosas así, ese cambio se diferencia mucho del que tiene lugar en las leyes positivas por obra de la epiqueya, porque en este caso la única que cesa es la obligación con relación a la misma materia, en cambio en el caso anterior [el de la ley natural] no sucede nada de eso sino que se quita la materia, y cambiada esta, desaparece la malicia" 56 .

\section{3) ALGUNOS PROBLEMAS RELACIONADOS CON EL MATRIMONIO}

A pesar de que, por las razones expuestas, no quepa admitir la equidad en la ley natural, queda, sin embargo, en pie un problema, pues hay casos en que parece que nos hallamos ante actos cuya materia y circunstancias ordinarias son suficientes para establecer una prohibición y, sin embargo, hay razones intrínsecas que parecen hacer cesar esa obligación. Para eso se pone Suárez en una situación hipotética, en la que la conservación de la especie entera depende de una sola pareja de individuos (o unos pocos), un ejemplo que, dicho sea de paso, muestra un modo de argumentar que es más propio de los autores modernos que de, por poner un ejemplo, santo Tomás.

"Tal es el precepto que prohíbe el matrimonio con la propia hermana, el cual en caso de extrema necesidad no obliga para la conservación de la especie. Lo mismo sucede con el precepto de no contraer matrimonio con una segunda mujer en vida de la primera, sobre todo si se consumó el primer matrimonio, pues en ese mismo caso de extrema necesidad del género humano, si la primera fuese estéril sería lícito tomar por mujer a la segunda" 57 .

La respuesta de Suárez a esta difícil cuestión muestra, en buena medida, por qué se lo llama Doctor Eximio, aunque no estoy seguro de que resulte convincente. Junto con recordar la doctrina de que las razones extrínsecas no bastan para quitar la malicia de un acto prohibido por un 
precepto natural negativo ${ }^{58}$, dice que, en los casos en que parece suceder así, no se trataría, en realidad de un precepto natural, sino de un precepto "próximo a natural y admitido y aprobado por la costumbre y, por consiguiente -en absoluto- de solo derecho de gentes y por tanto mudable o modificable en algún caso" 59 .

Nótese aquí que Suárez considera que el derecho de gentes no es propiamente derecho natural, postura en la que, a nuestro juicio, difiere de santo Tomás. En efecto, el Aquinate, no obstante algunas oscilaciones terminológicas debido a la necesidad de armonizar su doctrina con las enseñanzas de los textos romanos ${ }^{60}$, considera que esa categoría está incluida en los principios "derivados" de la ley natural, que son tan naturales como los primeros principios, solo que no son de hecho conocidos por todos los hombres ${ }^{61}$.

En todo caso, Suárez no se facilita en exceso su tarea y se pone en el caso en que no se resuelva la cuestión diciendo simplemente que la prohibición del incesto es de derecho de gentes (y, por tanto, positivo). En efecto, dice que, incluso en el caso en que se afirme que el precepto en cuestión "es sencillamente natural, su materia será no el acto tomado absolutamente y en abstracto sino con alguna circunstancia intrínseca quitada la cual la obligación pueda cesar, pero no por epiqueya sino por falta de la materia propia"62. De este modo, aunque estemos en presencia

58 "Se responde, sin embargo, que la norma general que se ha dado es verdadera, a saber, que mientras se conserva la materia de un precepto natural negativo, es imposible que en virtud de la epiqueya, por sola una causa o fin o necesidad extrínsecos, llegue a juzgarse lícito un acto prohibido: esto es lo que demuestran las razones y los ejemplos aducidos" (De Legibus II, XVI, 15 [179a]).

59 De Legibus II, XVI, 15 [179a]. Énfasis añadido.

60 Entre otras razones, los juristas romanos consideraban al derecho de gentes como no natural porque una de sus instituciones típicas era, según los textos, la esclavitud, que no corresponde a la libertad natural de los hombres. D’Ors, Álvaro (1980). "La actitud legislativa del Emperador Justiniano". En él mismo: Nuevos papeles sobre el oficio universitario. Madrid: Rialp, pp. 349-350.

61 Un resumen de esta discusión en: García-Huidobro, Joaquín (1993). Razón práctica y derecho natural. El iusnaturalismo de Tomás de Aquino. Valparaíso: Edeval, pp. 183-216. Tomás afirma la naturalidad del ius gentium en Sententia Libri Ethicorum V, 305: 73-75, n. 1019 (Spiazzi) y trata también el tema en la Suma Teológica I-II, 95, 4 ad 1 y II-II, 57, 3. Aunque en otros casos no suceda así, aquí hay que leer los pasajes de la Suma a la luz del Comentario, que en esta materia no sigue las enseñanzas aristotélicas, ya que el Estagirita ni tiene una noción de ley natural ni desarrolla una doctrina del ius gentium, sino que hace una elaboración propia, mucho más libre de la sujeción a los textos romanos que los pasajes correspondientes de la Suma. La razón de esa mayor libertad estriba en que en el Comentario la autoridad reconocida es básicamente la de Aristóteles, quien, al no pronunciarse sobre este tema, deja el camino libre al Aquinate para decir lo que le parezca más adecuado. Dicho con otras palabras, en esos pasajes del Comentario santo Tomás se halla más libre respecto del peso de las autoridades que en los pasajes paralelos de la Suma teológica.

62 De Legibus II, XVI, 15 [179a]. En II, XVII, 6 se vuelve a poner en este supuesto, al recoger, dentro de una discusión más amplia una opinión (que no hace suya explícitamente, pero que en buena medida parece aceptar) que dice que "en las mismas obras materialmente 
de preceptos naturales, ellos no prohibirían de manera absoluta el matrimonio entre hermanos o con una segunda mujer,

"sino que se prohíbe tal matrimonio en cuanto perjudicial a la naturaleza humana y de esta manera contrario a la honestidad natural en conformidad con la recta razón; pero en el caso propuesto de extrema necesidad esta razón cesa y comienza a ser un matrimonio muy conveniente a la naturaleza y por consiguiente honesto, porque se toma únicamente para la necesaria conservación de la especie, fin no extrínseco sino intrínseco a tal acto; de esta manera en esa ocasión se cambia la materia del precepto negativo"63.

Otro tanto sucede con el clásico ejemplo de la amputación de un miembro en caso de enfermedad, que no estaría prohibida en sí misma, sino solo "en cuanto perjudicial a la vida" 64 .

¿Cómo puede ser que lo que era malo pase, por un sorprendente e imperceptible cambio de materia, a ser "muy conveniente a la naturaleza", en un caso que es claramente diferente y más difícil que el asunto de la amputación de un miembro gangrenado? Para entenderlo,

"se deben considerar atentamente las cualidades y manera de ser de la materia, pues -según su capacidad- su manera de ser cambia moralmente en función del fin o de la necesidad del momento, porque la acción es tal que por su naturaleza exige su ordenamiento a tal fin de tal o de cual manera, y entonces la necesidad del momento redunda en la materia del precepto y la cambia, y con eso sucede que cesa la obligación del precepto natural: no porque el precepto no obligue siempre y en cada momento sin excepción en su materia propia, sino porque -una vez cambiada la materia- ya no tiene aplicación a ella tal precepto en cuanto natural" 65 .

En suma, Suárez piensa que en los casos señalados ha cambiado la materia y que el hecho de que un hombre y su hermana hayan llegado a ser los únicos y últimos representantes de la humanidad no es una razón extrínseca, sino que tiene que ver con el propósito mismo de la institu-

comunes con los brutos, la ley natural le prohíbe al hombre muchas cosas de las cuales el instinto no aparta a los brutos; por ejemplo, la ley natural prohíbe la unión libre, o sea, la simple fornicación, la unión con la propia madre o hermana, privaciones que no son comunes a los brutos".

De Legibus II, XVI, 15 [179a]. Énfasis añadido.

De Legibus II, XVI, 15 [179a].

De Legibus II, XVI, 15 [179b], una doctrina semejante se expone en relación a la apropiación en caso de necesidad de una cosa que en principio era ajena: De Legibus II, XV, 30 [172b]. 
ción matrimonial, que es la conservación de la especie. Otro tanto con el caso de quien toma una segunda mujer porque la primera es estéril y ese acto resulta necesario para la pervivencia de la especie. No estoy de acuerdo con esta conclusión. En lo que sigue abordaré este tema con más detalle.

\section{4) INCESTO Y POLIGAMIA}

Aunque Suárez no menciona el caso, es posible que su cierta liberalidad para tolerar el matrimonio entre hermanos cuando es imprescindible para la pervivencia de la especie, esté dada por una razón teológica, a saber, que si Adán y Eva fueron efectivamente la primera y única pareja, sus hijos e hijas debieron unirse entre ellos para propagar la especie, a no ser que se acepte el poligenismo, cosa que Suárez jamás habría hecho. Sucede que si Dios mismo les mandó crecer y multiplicarse quiere decir que esos actos incestuosos fueron queridos por Él, lo que resulta sorprendente, ya que la prohibición del incesto es una de las normas morales más difundidas en las diversas culturas ${ }^{66}$. La universalidad de esa prohibición podría hacernos pensar que su rechazo no obedece a mera convención sino que pertenece a lo justo natural, para decirlo en palabras de Aristóteles. El propio Estagirita, en la Política, califica al incesto como "el colmo de la indecencia" 67.

Un camino para resolver la dificultad consiste en preguntarse por la causa de la inmoralidad del incesto. La respuesta más fácil es acudir a las razones eugenésicas. Ellas permiten entender, además, por qué la prohibición del incesto ha alcanzado una difusión tan grande entre las diversas culturas, ya que todos los pueblos han podido experimentar o conocer sus consecuencias perjudiciales. Sin embargo, si se acepta lo que la teología cristiana enseña acerca del origen del hombre, su vida en el Paraíso y la caída original, es perfectamente posible pensar que en ese estadio primitivo de la naturaleza humana, donde a pesar de haberse cometido el pecado original esa naturaleza probablemente conservaba buena parte de su vigor primitivo, la unión entre hermanos no tenía por qué tener las consecuencias biológicas que tiene hoy. En ese sentido -si la única razón de la prohibición del incesto es eugenésica ${ }^{68}$ - entonces cabe pensar que, en un primer momento, la unión entre hermano y hermana no haya sido contraria a la naturaleza pero que sí haya empezado a serlo posteriormente. Esto no

66 Por todos: Moreno, Antonio (1994). Sangre y libertad: sistemas de parentesco, diversidad cultural y modos de reconocimiento personal. Madrid: Rialp, pp. 21-42.

Pol. II, 4, 1262a36.

68 Tomás de Aquino aporta razones de muy distinta naturaleza para prohibirlo: S. Th., II-II, 154,9 . 
resulta algo excesivamente excepcional: es perfectamente posible concebir la idea de ciertos preceptos morales que, no obstante su carácter natural, no hayan existido desde un principio, porque no se daban las condiciones fácticas de las que dependen. Si, por ejemplo, admitimos hipotéticamente un estado de comunidad original de bienes entre los hombres, donde, además, la codicia estaba ausente ${ }^{69}$, entonces en ese estado no existe la prohibición de hurtar, pues allí no puede darse la sustracción de lo ajeno. En cambio, una vez establecida, por buenas razones, la propiedad privada, entonces cabe afirmar que el hurto es contrario a la naturaleza. En esa dirección parece apuntar Suárez cuando dice que

"hay muchas cosas de derecho natural que no obligan si no es presuponiendo algo; así el precepto de no robar no tiene lugar si no es después de hecha la división de los bienes y de la propiedad [...] y la justicia de los contratos no tiene lugar si no es supuesto el comercio humano" 70 .

Así, en uno y otro caso habría una razón intrínseca, que explica el cambio de materia y nos permite decir que unas prohibiciones que hoy son naturales, las del incesto y del hurto, en un principio no lo hayan sido.

No sucedería lo mismo en el momento actual, donde la unión entre hermanos sí trae consigo graves consecuencias eugenésicas, que nos permiten decir que, si bien Suárez tiene razón al consignar que la institución matrimonial está orientada a la pervivencia de la especie, esa perpetuación no puede hacerse de un modo que menoscabe la integridad misma de la especie humana.

A la razón anterior podrían agregarse los argumentos que da santo Tomás para oponerse a la unión conyugal entre los hermanos, que en un caso como el que propone Suárez me parece que tendrían menos fuerza: la armonía interna de la familia se vería afectada si una pasión tan fuerte como la sexual se ejercitara entre personas que están muy próximas ${ }^{71}$. Esta es, por decirlo así, una razón de conveniencia, que no se daría en caso de estar en peligro la subsistencia de la entera especie humana ${ }^{72}$.

69 Así, por ejemplo, dice santo Tomás que "en el estado de inocencia estaban de tal modo armonizadas las voluntades de los hombres, que cada uno hubiese tomado del bien común lo que le correspondía, sin peligro alguno de discordia" (S. Th. I, 98, 1 ad 3).

De Legibus II, XVII, 9 [183b].

S. Th., II-II, 154, 9.

Santo Tomás explica que la unión entre hermanos tiene una menos gravedad moral que la que se produce entre padres e hijos: "en las personas que no están ligadas entre sí próximamente, sino por su relación con los padres, tampoco reviste el pecado tan suma gravedad e indecencia, sino que esta varía según las costumbres y la ley, sea ésta humana o divina. Ya hemos dicho (a. 2) que el uso del placer venéreo, al estar ordenado al bien común, está 
A diferencia de Suárez, cabe pensar que la perpetuación de la especie, si bien es una finalidad intrínseca al matrimonio, no es un motivo suficiente para hacer cambiar la materia del acto de unirse conyugalmente con la propia hermana, transformándolo en "muy conveniente a la naturaleza", dado que sus graves consecuencias biológicas llevan a cuestionar esa conveniencia. Si esto es así, entonces, de producirse una situación de extinción de la humanidad como la que parece tener hipotéticamente presente nuestro autor, en la que solo sobreviven dos hermanos, la actitud más correcta no es recurrir al incesto sino simplemente aceptar que ha llegado el final y que no depende de uno hacer cualquier cosa por evitarlo, pues, como enseña el Digesto, lo moralmente inaceptable se asimila a lo físicamente imposible:

"Los hechos que ofenden la piedad, la estimación, nuestro pudor, y, para decirlo de una vez, que se hacen contra las buenas costumbres, se ha de creer que ni podemos hacerlos"73.

El caso de la poligamia es distinto (y quizá más sencillo de resolver para los escolásticos), pero podría ser solucionado en la forma en que lo hace Suárez, que no es muy diferente de la elegida por santo Tomás. Ella lleva a considerar la unidad matrimonial como un medio para conseguir la propagación de la especie asegurando, a la vez, la paz de la familia. Estos resultados bien podrían conseguirse por otro camino, aunque de manera menos perfecta. Una solución semejante es difícilmente aceptable para nuestra mentalidad, pero, en todo caso, se apoya en razones distintas de una eventual aceptación del incesto.

En todo caso, estemos o no de acuerdo con la solución que Suárez entrega para estos problemas relativos al matrimonio, queda claro, primero, que la equidad no procede en el caso de la ley natural y, segundo, que resulta fundamental poner atención a la materia de que se trata, cuyo cambio trae consigo que un determinado precepto deje de aplicarse a ese caso y deba resolverse acudiendo a otro:

sujeto a la ley. Por eso, como dice San Agustín en XV De Civ. Dei 42, 'el comercio carnal entre hermanos y hermanas, si bien fue recomendable antiguamente, por venir impuesto por la necesidad, pasó luego a ser reprobable por prohibirlo la religión'” (S. Th. II-II, 154, 9c). Con todo, el hecho que la ley divina o la humana influyan en la determinación de la gravedad no significa que esta derive únicamente de una determinación convencional. De hecho, más adelante llega a afirmar que "si uno abusa de una persona unida a él mediante lazos espirituales, comete sacrilegio semejante al incesto" ( $S$. Th. II-II, 154, 10 ad 2), lo que muestra la gravedad que santo Tomás atribuye a esta conducta (más argumentos en $S$. Th. II-II, 154, 12 c).

73 Digesto XXVIII, 7, 15. 
"Así pues, se deben considerar atentamente las cualidades y manera de ser de la materia, pues -según su capacidad-su manera de ser cambia moralmente en función del fin o de la necesidad del momento, porque la acción es tal que por su naturaleza exige su ordenamiento a tal fin de tal o de cual manera, y entonces la necesidad del momento redunda en la materia del precepto y la cambia, y con eso sucede que cesa la obligación del precepto natural: no porque el precepto no obligue siempre y en cada momento sin excepción en su materia propia, sino porque - una vez cambiada la materia- ya no tiene aplicación a ella tal precepto en cuanto natural" 74 .

En suma, podemos concluir que frente al caso del matrimonio y otros semejantes, Suárez busca resolver las dificultades que habían llevado a algunos autores anteriores a él a pensar que la equidad no solo procede en el caso de la ley positiva, sino también a propósito de la ley natural. Si lo que se ha dicho aquí es verdad, Suárez tiene razón al afirmar que no procede la equidad cuando se trata de la ley natural y que los casos indicados por los autores se resuelven por la vía de la interpretación. Dicha labor tiene lugar tratándose del conocimiento de la realidad en la que se dará la acción y también, según nuestro autor, respecto de los principios que la orientan. En todo caso, los pasajes del De Legibus que se han comentado dan cuenta de un análisis de gran sutileza, que permite no solo delimitar los ámbitos de la interpretación y la equidad, muchas veces confundidos por los autores precedentes, sino también poner de relieve la distinción entre circunstancias internas y externas del acto, que será fundamental para resolver los problemas que plantea la admisión de la doctrina de los actos intrínsecamente malos, que juega un papel fundamental en la tradición central ética de Occidente y que hoy es objeto de importantes debates.

\section{BIBLIOGRAFÍA}

- Aristóteles (2007). Ética a Nicómaco, V, 7 1134b18-1135a5, traducción de E. Sinnot, Buenos Aires: Coligüe.

- Aristóteles (2007). Retórica, introducción, traducción y notas de Quintín Racionero, Madrid: Gredos.

- Corso de Estrada, Laura (2008). Naturaleza y vida moral. Un estudio sobre el influjo filosófico de Marco Tulio Cicerón en Tomás de Aquino. Pamplona: Eunsa.

$74 \quad$ De Legibus II, XVI, 15 [179b]. 
- De Soto, Domingo (1922). Tratado de la Justicia y del Derecho, I, 4, 1, Madrid: Reus.

- D’ors, Álvaro (1980). "La actitud legislativa del Emperador Justiniano". En él mismo: Nuevos papeles sobre el oficio universitario. Madrid: Rialp, pp. 349-350.

- Finnis, John (1992). Absolutos morales, Barcelona: Ediciones Internacionales Universitarias.

- Gadamer, Hans-Georg (1990). Wahrheit und Methode. Grundzüge einer philosophischen Hermeneutik, 6a edición. Tübingen: J. C. B. Mohr, p. 323 (trad. A. A. Aparicio y R. de Agapito, Salamanca, 2005).

- _ (1993). „Hermeneutik”. En él mismo: Gesammelte Werke 2. Hermeneutik II, Tübingen: J. C. B. Mohr (Paul Siebeck).

- (2002). Verdad y Método II. 5a edición, trad. de M. Olasagasti, Salamanca: Sígueme.

- Giers, Joachim (1958). Die Gerechtigkeitslehre des jungen Suárez. Edition und Untersuchung seiner römischen Vorlesungen De Iustitua et Iure. Freiburg: Herder.

- Herrera, Hugo (2000). Verdad y práctica. Cinco ensayos sobre la fundamentación de la praxis. Valparaíso: Edeval.

- Höfre, Ottfried (1988). "Derecho natural sin falacia naturalista: un programa jusfilosófico". En él mismo: Estudios sobre teoría del derecho y la justicia. Barcelona: Editorial Alfa, pp. 105-132.

- Hume, David (1977). Tratado de la naturaleza humana, vol. II, Madrid: Editora Nacional

- Kaufmann, Arthur (1976). Analogía y naturaleza de la cosa. Hacia una teoría de la comprensión jurídica. Santiago: Editorial Jurídica de Chile.

- Massini, Carlos I. (1995). La falacia de la falacia naturalista, Mendoza: Edium.

- _ (1997). "La nueva escuela anglosajona de Derecho Natural”, en Revista de Ciencias Sociales, No 41, pp. 371-392.

- Moreno, Antonio (1994). Sangre y libertad: sistemas de parentesco, diversidad cultural y modos de reconocimiento personal. Madrid: Rialp, pp. 21-42.

- Ollero, Andrés (1974). "Hermenéutica jurídica y ontología en Tomás de Aquino". Anuario de Estudios Sociales y Jurídicos, III, pp. 289-303. (1973) "Equidad, derecho, ley". Anales de la Cátedra Francisco Suárez, 13, pp. 163-178.

- Platón (1997). Eutifrón, Santiago: Universitaria, traducción, análisis y notas: Alfonso Gómez-Lobo.

- Scherz, Luis T. (2006). Das Naturgesetz bei Thomas von Aquin und die Tentatio Stoicorum, heutige Auffassungen eines umstrittenen Begriffs, Tübingen: Francke Verlag. 
- Spaemann, Robert (2001). Grenzen. Zur ethischen Dimension des Handelns. Stuttgart: Klett-Cotta.

- SuÁrez, Francisco (1967). Tratado de las leyes y de Dios Legislador en diez libros (traducción de J. R. Muniozguren). Madrid: Instituto de Estudios Políticos.

- Tomás de Aquino, Suma Teológica, I-II, 90, 2.

- Voegelin, Eric (2006). „Das Rechte von Natur”, en Voegelin, Eric: Anamnesis. Zur Theorie der Geschichte und Politik. FreiburgMünchen: Alber, pp. 117-133. 